Macedonian Pharmaceutical Bulletin, 66 (Suppl 1) 191 - 192 (2020)

Online ISSN 1857 - 8969

UDC: $615.47 .015 .2: 615.2]: 340.13$

DOI: 10.33320/maced.pharm.bull.2020.66.03.095

Short communication

\title{
Drug-device combinations and Article 117: more questions than answers?
}

\author{
Elena Ivanovska ${ }^{1}$, Jelena Lazova ${ }^{1}$, Suzana Trajkovic Jolevska ${ }^{2}$, \\ Jasmina Tonic Ribarska ${ }^{2}$, Nada Popstefanova ${ }^{1}$, Marija Davcheva Jovanoska ${ }^{1}$ \\ ${ }^{1}$ Pharmaceutical Chemical Cosmetic Industry ALKALOID AD Skopje, Blvd. Aleksandar Makedonski 12, \\ 1000 Skopje, Republic of North Macedonia \\ ${ }^{2}$ Faculty of Pharmacy, Ss Cyril and Methodius University, Str. Majka Tereza 47, 1000 Skopje, \\ Republic of North Macedonia
}

\section{Introduction}

While the medical device industry is dealing with the medical device regulation (MDR) and changes it brings along, the drug-device combination products (DDCs) are facing an additional uncertainty: the provisions of Article 117. In lay terms this article basically says that, as from May 2020, all new DDCs should be in compliance not only with the legislation requirements for medicinal products, but as well as with the requirements of the new regulation for medical devices.

\section{Regulatory context}

Article 117 of the MDR 2017/745 introduces a new requirement for medicines with an integral device (CoE, 2017). The marketing authorisation application (MAA) should include results of the assessment of the conformity of the device part with the relevant general safety and performance requirements (GSPRs) set out in Annex I in a form of a CE certificate or declaration of conformity for the device or, if it is not CE marked but would need to be certified if marketed separately, the applicant must include an opinion from a Notified Body (NB) on the conformity of the device (EMA, 2020).

\section{Defining drug-device combination products}

The MDR does not provide clear definition of drug-device combination products, but the European Medicines Agency (EMA) has managed to provide some description and classification in the draft guideline that they have issued. According to this guideline terms 'integral' and 'non-integral' are used to describe the DDCs (EMA, 2019a).

\section{Guidance and open questions}

Earlier in 2019, EMA published a Q\&A guide, which addresses several key issues, but still there are points that remain to be further resolved, such as: Involvement of $\mathrm{NB}$ designated to carry out the conformity assessment procedure for the particular medical device type(s) where certification is sought.

- Limited number of NBs are certified under the MDR, with limited scope; affecting not only the possibility of finding the proper NB for performing the assessment but also the timeframes for submission of MAA.

MAAs for these products will be jointly assessed by competent authorities and NBs.

- What happens if the reviewers disagree on one or more of the overlapping combination product attributes or risks (EMA, 2019b; Pillar, 2019).

\footnotetext{
*eivanovska@alkaloid.com.mk
} 
If the device is governed by the medicinal products legislation, then MDR obligations related to labelling and UDI are not required and should not be applied to the package of the combination product.

- This exclusion may not be in the interest of safe products for patients and other users since labelling requirements for medical devices differ from the requirements for medicinal products.

Confirmation of compliance with MDR is based on assessment of Annex I solely but it does not include evaluation of device's clinical data.

- Clinical data on the device may be very useful for performing clinical studies on the DDC (EMA, 2019a; Steffen, 2018).

\section{What about the device point of view?}

All of the EMA guidance on assuring conformity of the device is mainly focused on which documents should be provided, who is to provide them and where should they be placed on the CTD, but there are more important issues as how to assure the compliance of the device with Annex I of the MDR.

The current situation is rather confusing when looked also from medical device manufacturer point of view. One example is the use of harmonised standards, which are essential for demonstrating compliance with GSPRs. When we look closer, it becomes apparent that there is a significant amount of technical standards that demonstrate compliance with the GSPRs but that are not harmonized. Also, the recent harmonization was done under the MDD without consideration for the MDR. In order to get the necessary harmonization started, the European Commission has to issue respective standardization requests as well as conduct a defined review process considering the GSPRs. While this overall process is time consuming and requires involvement of several parties it is expected that many standards will not be harmonized under the MDR in time.

Furthermore, no Common Specifications have been published that need to be considered in the context of a single integral DDC.

The applicability of the GSPRs to a DDC is partially hard to break down to the device part only. In fact, the interaction of device and drug product needs to be considered for many requirements such as to test functionality characteristics, or stability testing or obtaining clinical data (Schommer, 2019).

\section{Conclusion}

For DDCs manufacturers the continuous vigilance of the everyday updates and changes in the legislation would now play a key role in providing quality MAA documentation on timely manner.

A lot of work still needs to be finished; a lot of questions will probably be answered throughout the processes. But in any case it is certain that all involved entities are putting all their efforts into providing the best possible solutions for ensuring safe products for patients and users, which, after all, is the ultimate purpose of all legislation changes.

\section{References}

Council of Europe, 2017. Regulation (EU) 2017/745 of the European Parliament and of the Council of 5 April 2017 on medical devices, amending Directive 2001/83/EC, Regulation (EC) No 178/2002 and Regulation (EC) No 1223/2009 and repealing Council Directives 90/385/EEC and 93/42/EEC. Official Journal of the EU. L 117, 1-175.

European Medicines Agency, 2019a. Draft Guideline on the quality requirements for drug-device combinations. EMA/CHMP/QWP/BWP/259165/ 2019.

European Medicines Agency. 2019b. Questions \& Answers on Implementation of the Medical Devices and In Vitro Diagnostic Medical Devices Regulations ((EU) 2017/745 and (EU) 2017/746). EMA/37991/2019.

European Medicines Agency, 2020. Medical devices. Available at: https://www.ema.europa.eu/en/humanregulatory/overview/medical-devices (Last accessed on 01.03.2020).

Pillar, M., 2019. Why EU's New Med Device Regs Matter To Biopharma. Bioprocess online. Available at: https://www.bioprocessonline.com/doc/why-eu-snew-med-device-regs-matter-to-biopharma-0001

(Last accessed on 01.03.2020).

Schommer, C., 2019. Master Thesis. MDR's Article 117: Regulatory Strategy to Comply With the General Safety and Performance Requirements Set Out in Annex I in the Light of a Single Integral Drug Device Combination. P.51. Available at: https://www.dgra.de /media/pdf/studium/masterthesis/master_schommer caroline_2019.pdf (Last accessed on 01.03.2020).

Steffen, B.U., 2018. MDR Article 117 - a look into the Crystal Ball. Available at: https://www. linkedin.com/pulse/mdr-article-117-look-crystal-ballpart-1-beat-u-steffen (Last accessed on 01.03.2020).

Maced. Pharm. Bull. 66 (Suppl 1) 191 - 192 (2020) 